This is the author's final, peer-reviewed manuscript as accepted for publication. The publisher-formatted version may be available through the publisher's web site or your institution's library.

\title{
Gas leakage and distribution characteristics of methyl bromide and sulfuryl fluoride during fumigations in a pilot flour mill
}

Watcharapol Chayaprasert, Dirk E. Maier, Bhadriraju Subramanyam, Michelle Hartzer

\section{How to cite this manuscript}

If you make reference to this version of the manuscript, use the following information:

Chayaprasert, W., Maier, D. E., Subramanyam, B., \& Hartzer, M. (2012). Gas leakage and distribution characteristics of methyl bromide and sulfuryl fluoride during fumigations in a pilot flour mill. Retrieved from http://krex.ksu.edu

\section{Published Version Information}

Citation: Chayaprasert, W., Maier, D. E., Subramanyam, B., \& Hartzer, M. (2012). Gas leakage and distribution characteristics of methyl bromide and sulfuryl fluoride during fumigations in a pilot flour mill. Journal of Stored Products Research, 50, 1-7.

Copyright: (c) 2012 Elsevier Ltd.

Digital Object Identifier (DOI): doi:10.1016/j.jspr.2012.03.002

Publisher's Link:

http://www.sciencedirect.com/science/article/pii/S0022474X12000197

This item was retrieved from the K-State Research Exchange (K-REx), the institutional repository of Kansas State University. K-REx is available at http://krex.ksu.edu 


\section{Highlights}

- The half-loss times (HLTs) during three methyl bromide (MB) and three sulfuryl fluoride (SF) fumigations were monitored.

- Concentrations of both fumigants within the mill ranged from 2 to $7 \mathrm{~g} / \mathrm{m}^{3}$.

- The observed HLTs for the MB and SF fumigations were in the range of 3.61 to $28.64 \mathrm{~h}$ and 9.97 to $31.65 \mathrm{~h}$, respectively.

- HLTs were inversely related only to wind speeds. 
1 Revised version

2

3

4

5

6

7

8

fluoride during fumigations in a pilot flour mill

10

11

12 Watcharapol Chayaprasert ${ }^{1,2}$, Dirk E. Maier ${ }^{1}$, Bhadriraju Subramanyam ${ }^{1, \star}$, and Michelle Hartzer $^{1}$

$14{ }^{1}$ Department of Grain Science and Industry, Kansas State University, Manhattan, Kansas, 66506, USA

$16{ }^{2}$ Department of Agricultural Engineering, Faculty of Engineering at Kamphaengsaen,

17 Kasetsart University - Kamphaengsaen Campus, Nakhon Pathom, 73140, Thailand

22 *Corresponding author: Tel: +1 785-532-7010, E-mail: sbhadrir@k-state.edu

23 


\section{Abstract}

The half-loss time (HLT) is used as an indicator to quantify gas leakage rates

26 during methyl bromide (MB) and sulfuryl fluoride (SF) fumigations. Comparisons of

27 HLTs between three MB and three SF fumigations were quantified in the Hal Ross pilot

28 flour mill, Department of Grain Science and Industry, Kansas State University, USA.

29 The sealing quality or gas tightness of the mill before each fumigation was verified by a

30 pressurization test. Fumigant concentrations during the six fumigations were monitored

31 continuously at 30 locations among the five mill floors during the $24 \mathrm{~h}$ fumigation period.

32 A weather station on the mill roof monitored barometric pressure, wind speed and

33 direction, temperature, and relative humidity. A data logger on each mill floor recorded

34 temperature and relative humidity. The pressurization test showed that the relationship

35 between airflow rate and building static pressure varied among the fumigations despite

36 the same areas being sealed by two separate fumigation service providers due to

37 environmental conditions not being identical among the fumigations. Concentrations of

38 both fumigants within the mill ranged from 2 to $7 \mathrm{~g} / \mathrm{m}^{3}$. The observed HLTs for the MB

39 and SF fumigations were in the range of 3.61 to $28.64 \mathrm{~h}$ and 9.97 to $31.65 \mathrm{~h}$,

40 respectively, and were inversely related only to wind speeds during fumigation and not

41 any other environmental conditions recorded. In our study, the fumigant leakage rate

42 was found to be predominantly a function of wind speed rather than inherent gas

43 characteristics of MB and SF.

44

45 Keywords: Structural fumigation, Sealing quality, Leakage rates, Gas dynamics, Half-

46 loss time, Wind speed 


\section{Introduction}

A structural fumigation is considered successful when the target dosage for an

50 effective kill of all insect life stages is achieved. The dosage is a cumulative product of

51 the fumigant concentration (C) over the exposure time (t), and is referred as the $\mathrm{Ct}$

52 product (Kenaga, 1961; Gandy and Chanter, 1976; Annis, 1999; Bell et al., 1999). The

53 Ct product is a function of the amount of released fumigant, exposure time, and

54 fumigant leakage rate. Fumigant leakage rate is quantified by the half-loss time (HLT),

55 which is the time taken in hours (h) for $50 \%$ loss of the total fumigant concentration from

56 the structure being fumigated. The gas leakage rate and HLTs are inversely related. In

57 commercial fumigations, an ideal HLT should be $>15 \mathrm{~h}$, but realistic HLTs may range

58 from 5 to $22 \mathrm{~h}$ (Chayaprasert, 2007).

$59 \quad$ Methyl bromide (MB) has been the primary fumigant used for structural

60 fumigation in food-processing facilities such as flour mills (Taylor, 1994). Sulfuryl

61 fluoride (SF) was registered in the United States for use in food-processing facilities in

62 January 2004 under the trade name ProFume ${ }^{\circledR}$ by Dow AgroSciences LLC,

63 Indianapolis, Indiana, USA. It is a viable replacement for MB, which was phased out in

64 the United States in 2005 due to its adverse effects on stratospheric ozone, but

65 continues to be available through the critical use exemption (CUE) process (US-EPA, 66 2010).

67 A majority of fumigation experiments conducted in commercial food-processing

68 facilities focused on efficacy against insects and/or on insect population rebounds

69 following the treatment (Drinkall et al., 2003; Reichmuth et al., 2003; Bell et al., 2004;

70 Campbell and Arbogast, 2004; Drinkall et al., 2004; Small, 2007). Chayaprasert (2007) 
71 reported that fumigant concentrations, indoor temperature and relative humidity, and

72 outside weather conditions alone cannot explain fumigant leakage rates without taking

73 sealing quality into consideration. Chayaprasert and Maier (2010) used experimental

74 building pressurization tests and computational fluid dynamics (CFD) model simulations

75 to evaluate the effect of building sealing quality or gas-tightness and weather conditions

76 on SF leakage rates. They concluded that sealing quality and environmental factors

77 should be considered when comparing structural fumigants. Cryer (2008) used CFD

78 simulations to compare leakage characteristics between MB and SF from two flour mills

79 subjected to various hypothetical fixed wind speeds, and found that under similar

80 environmental conditions the HLTs for MB and SF were nearly identical. A computer

81 simulation study by Chayaprasert et al. (2009) also supported this view.

82 Typically when HLTs during commercial structural fumigations are compared,

83 environmental conditions are not taken into consideration by fumigators. Additionally,

84 sealing quality effectiveness is rarely quantified whenever fumigation is done making it

85 difficult to interpret effectiveness of practical structural treatments. Therefore, the

86 current study objectives were to validate computer simulation results with empirical

87 measurements of gas leakage and distribution in a pilot flour mill subjected to MB and

88 SF fumigations and to relate gas leakage rates to environmental conditions.

\section{2. Materials and methods}

\subsection{Mill fumigation treatments}

91

The state-of-the art Hal Ross pilot flour mill belonging to the Department of Grain

92 Science and Industry, Kansas State University, Manhattan, Kansas, USA, was used for 
93 the present study. The mill has five floors that occupy a total volume of $\sim 9,628 \mathrm{~m}^{3}$, and

94 Fig. 1 shows the mill exterior and generic floor plan which is essentially similar across

95 the floors. All mill floors have interconnected air supply vents, in addition to openings

96 between floors to accommodate equipment. Three MB and three SF fumigations were

97 conducted during 2009 and 2010. Each pair of MB and SF fumigations was carried out

98 within a three-week time span to ensure comparisons under approximately similar

99 environmental conditions. The fumigations were split between two separate professional

100 fumigation service providers following label directions and safety precautions. The mill

101 was cleaned and sealed prior to all fumigations. We did not compare the sealing

102 material and sealants used by these two service providers. Two $0.51-\mathrm{m}$ diameter fans

103 were placed on each floor to facilitate gas distribution. These fans were in operation

104 during the entire $24 \mathrm{~h}$ exposure period. One fumigant introduction point was selected on

105 every floor. All of the stairwell doors were open with some exceptions. The first and

106 second floor doors were closed during the second SF fumigation, and the doors on

107 every floor were closed during the third SF fumigation to reduce fumigant leakage.

108 These decisions were made by the fumigators. The date of fumigation, amount

109 introduced on each floor, and the introduction time are shown in Table 1.

111 Six gas monitoring lines of different colors, made of nylon tubes with 4.3-mm

112 internal diameter, were placed on each mill floor. One line was placed on the mill floor at

113 the southwest corner and another line was placed near the ceiling at the northeast

114 corner. The other four monitoring lines were evenly distributed throughout each floor

115 both inside and outside of milling equipment, where there were bioassay boxes with 
116 different life stages of the red flour beetle. Two or three of these lines were inserted into

117 different machines where bioassay boxes were located. The bioassay results are being

118 reported elsewhere and are not relevant to the objectives of this paper. The equipment

119 was closed after placement of the monitoring lines. Fumigant concentrations at 10

120 locations (2 per floor) were monitored automatically every 20 minutes by the Spectros

121 Single Point Monitor (Spectros Instruments, Hopedale, Massachusetts, USA). The

122 remaining 20 locations was monitored manually on an hourly basis by using either the

123 Spectros Instruments Single Point Monitor or Fumiscope (Key Chemical and

124 Equipment, Clearwater, Florid, USA) throughout the $24 \mathrm{~h}$ exposure period.

125 The environmental conditions during each fumigation were monitored using a

$126 \mathrm{HOBO}^{\circledR} \mathrm{U} 30$ weather station (Onset Computer Corporation, Bourne, Massachusetts,

127 USA), which was installed on the mill roof to record barometric pressure, wind speed

128 and direction, temperature, and relative humidity at one-minuet intervals. $\mathrm{A} \mathrm{HOBO}{ }^{\circledR} \mathrm{H} 8$

129 data logger (Onset Computer Corporation) on each mill monitored temperature and

130 relative humidity at one-minute intervals. During the third MB fumigation the weather

131 station failed to record wind speed, and wind speed data for this particular fumigation

132 were obtained from the weather station installed on the ground at the Agronomy Farm

133 located about $500 \mathrm{~m}$ to the west of the mill.

134 2.2. Pressurization test

135 One to two hours before each fumigation, the building sealing quality or gas

136 tightness was quantitatively evaluated by a pressurization test. The pressurization test

137 was conducted using the E3 blower door fan (Infiltec, Waynesboro, Virginia, USA). The

138 fan is capable of delivering a maximum airflow rate of $2.57 \mathrm{~m}^{3} / \mathrm{s}$. The fan was attached 
139 to one of the exit doors on either the east or west side. During each pressurization test,

140 the building was subjected to different pressure levels between 10 and $140 \mathrm{~Pa}$ by

141 increasing the fan airflow rate. At each pressure level, the flow rate through the fan and

142 the static pressure difference across the blower door were measured by the DM4 micro-

143 manometer (Infiltec, Waynesboro, Virginia, USA).

\section{2.3. Data analysis}

145 The gas-tightness characteristic of the mill was determined by fitting a nonlinear

146 regression model (Equation 1) to the relationship between the flow rate across the

147 pressurization fan $\left(Q, \mathrm{~m}^{3} / \mathrm{s}\right)$ and the static pressure difference across the blower door

148 (p, Pa) (ASHRAE, 2001):

$$
Q=b p^{n}
$$

150 where, $b$ is the flow coefficient $\left(\mathrm{m}^{3} / \mathrm{s}-\mathrm{Pa}^{\mathrm{n}}\right)$ and $n$ is a dimensionless pressure exponent.

151 All possible pair-wise combinations based on three pressurization tests for MB and

152 three for SF fumigations were compared by testing the deviation of individual models

153 (Equation 1) fit to the flow rate and pressure data to a pooled model (Draper and Smith,

154 1981). A significant difference $(P<0.05)$ between pooled and individual models

155 indicated that the relationship between flow rate and pressure was significantly different

156 between the two pressurization tests being compared. The six fumigations between MB

157 and SF resulted in 15 pair-wise comparisons.

158 The HLTs observed from the fumigations were estimated by a first-order kinetic

159 equation (Equation 2) of gas concentration readings over time (Banks et al., 1983;

160 Chayaprasert et al., 2008; Cryer, 2008): 


$$
C_{t}=\frac{C_{i}}{2^{\frac{t}{H L T}}}
$$

162 where, $C_{t}$ is the current concentration $\left(\mathrm{g} / \mathrm{m}^{3}\right)$ at the elapsed time $t(\mathrm{~h})$ and $C_{i}$ is the initial 163 concentration $\left(\mathrm{g} / \mathrm{m}^{3}\right)$.

164 A direct comparison of the resulting HLTs between the MB and SF fumigations 165 could not be made without taking into account all of the weather conditions. Banks and 166 Annis (1984) showed that the overall ventilation rate $\left(\mathrm{d}^{-1}\right)$, which is defined as the total 167 volume of the enclosure divided by the volumetric gas loss rate during fumigation in 168 grain storages, is a summation of individual ventilation rates associated with barometric 169 pressure, buoyancy, and wind forces. One common method used to calculate air 170 infiltration rates, $q\left(\mathrm{~m}^{3} / \mathrm{s}\right)$, in buildings is the superposition method (Equation 3 ) in which

171 the wind and stack effects are determined separately and then combined together

172 based on a predefined correlation (ASHRAE, 2001):

$$
q=\frac{A_{L}}{1000} \sqrt{c_{s} \Delta T+c_{w} U^{2}}
$$

174 where, $A_{L}$ is the effective leakage area $\left(\mathrm{cm}^{2}\right), c_{s}$ is the stack coefficient $\left((\mathrm{L} / \mathrm{s})^{2} / \mathrm{cm}^{4}-\mathrm{K}\right), c_{w}$

175 is the wind coefficient $\left((\mathrm{L} / \mathrm{s})^{2} / \mathrm{cm}^{4}-(\mathrm{m} / \mathrm{s})^{2}\right), \Delta T$ is the average indoor-outdoor temperature

176 difference $(K)$, and $U$ is the average local wind speed $(\mathrm{m} / \mathrm{s})$. HLT and $q$ are related as

177 shown in Equation 4 (Banks et al., 1983; Chayaprasert, 2007):

$$
H L T=\frac{V}{q} \frac{\ln (2)}{3600}
$$

179 where, $V$ is the volume of the fumigated building $\left(\mathrm{m}^{3}\right)$. Equations 3 and 4 were used to 180 establish any correlations between the HLTs calculated from Equation 2 and the 181 measured indoor-outdoor temperature differences and prevailing wind speeds. 
183 because of lack of relationship between fumigant concentration and barometric

184 pressure. Wind direction can affect the fumigant leakage rate when tall structures are

185 neighboring fumigated structures (e.g., grain silos nearby a fumigated flour mill) or when

186 areas of leakage within fumigated structures are not evenly distributed on all sides

187 (Cryer, 2008; Chayaprasert et al., 2009). At the Hal Ross flour mill there were no

188 structures within a $200-\mathrm{m}$ radius taller than half of the mill's height to alter wind direction

189 and influence gas leakage rates. Wind direction was, therefore, neglected in the

190 analysis of gas leakage rates.

191 3. Results and discussion

The plots of the pressure-airflow rate curves representing sealing effectiveness

193 of all fumigation experiments are shown in Figure 2. Equation 1 satisfactorily described

194 the pressure and airflow data $\left(r^{2}=0.819\right.$ to 0.995$)$ (Table 2$)$. The coefficients $b$ ranged

195 from 0.098 to 0.279 while the coefficient $n$ ranged from 0.445 to 0.655 . The gas-

196 tightness was similar only for the first MB and first SF fumigations $(F=1.06$; $\mathrm{df}=2,68$;

$197 P=0.351)$. The gas-tightness was significantly different for the remaining 14 pair-wise

198 comparisons $(F$, range $=8.49-273.63 ; \mathrm{df}$, range $=2,68-2,145 ; P<0.0005)$. This

199 could be attributed to differences in environmental conditions (see below) during each of

200 the fumigations, because data used in Equation 1 could not be corrected for differences

201 in environmental conditions. The result of the pressurization test for the second SF

202 fumigation was adversely affected by strong prevailing winds (6 to $8 \mathrm{~m} / \mathrm{s}$ ) during the test

203 resulting in more scattered data points. However, the lower boundary of the scattered

204 data points, which indicates the highest building gas-tightness, coincided with similar 
205 pressure-airflow rate curves for the five other fumigations. In general, the pressurization 206 test results suggested that the differences in the HLTs were not caused by variations in 207 sealing quality but by the outside environmental conditions.

208 Substantial variations in barometric pressure, outside temperature, and outside 209 relative humidity were observed among fumigations (Figure $3 \mathrm{~A}-\mathrm{C}$ ). The barometric 210 pressure curves in Figure 3A were adjusted for the barometric pressure reduction due 211 to the difference in height between the weather station on the mill roof and the ground.

212 The average values of barometric pressure, outside temperature, and relative humidity 213 between the fumigations ranged from 971 to $984 \mathrm{mbar}, 13$ to $26^{\circ} \mathrm{C}$, and 63 to $84 \%$,

214 respectively. Within each fumigation the differences between the highest and lowest

215 values of barometric pressure, outside temperature, and relative humidity were

216 approximately 3 to 9 mbar, 5 to $15^{\circ} \mathrm{C}$ and 30 to $60 \%$, respectively. The inside

217 temperature and relative humidity were, however, stable during the fumigations (Table

218 3). On each floor the inside temperature and relative humidity generally varied by less

219 than $1{ }^{\circ} \mathrm{C}$ and $10 \%$, respectively, and the differences in the inside temperature and

220 relative humidity among floors were less than $4^{\circ} \mathrm{C}$ and $20 \%$, respectively. The inside

221 temperatures were either equal to or higher than the outside temperatures with a

222 maximum difference of at least $10^{\circ} \mathrm{C}$, except for the first and second $\mathrm{MB}$ fumigations,

223 where for a few hours, the opposite occurred. These findings suggested that at the gas-

224 tightness level achieved in this study air infiltration did not have an effect on the thermal

225 changes inside the flour mill. In addition to preventing rapid gas loss, good sealing

226 quality helps increase fumigation efficacy against insects and helps maintain stable

227 temperatures inside a fumigated building irrespective of outside temperature changes. 
The fumigant concentrations over time near the ceiling across the five mill floors

229 for each of the fumigations are illustrated in Figure 4. For the MB and SF fumigations,

230 differences in fumigant concentrations within each floor were less than 3 and $5 \mathrm{~g} / \mathrm{m}^{3}$,

231 respectively (data not shown). Initially, the fumigant concentrations increased rapidly

232 and distributed well among the mill floors, after which the concentrations gradually

233 decreased over time. However, gas concentrations at one monitoring location in an

234 ingredient mixing drum on the third floor was an exception to this general observation.

235 During the first MB and all SF fumigations, the gas concentrations inside the mixing

236 drum did not decrease as fast as the other locations because of restricted gas

237 movement. The sudden peaks in gas concentrations $15 \mathrm{~h}$ after the initial fumigant

238 introduction in the first and third MB fumigations were due to adding more gas (Table 1).

239 SF gas was also added during the third fumigation at $14.5 \mathrm{~h}$ into the fumigation, but gas

240 monitoring data did not show any sudden peaks. The concentration differences within

241 the entire mill were between 2 and $7 \mathrm{~g} / \mathrm{m}^{3}$. Even gas distribution was established

242 throughout the mill within the first $4 \mathrm{~h}$, except for the second and third SF fumigations in

243 which it took at least $10 \mathrm{~h}$. The longer time for gas to equilibrate within the structure may

244 be due to the stairwell doors being closed during these two fumigations, making it more

245 difficult for the fumigant to circulate quickly among mill floors. In some structures,

246 partitioning very leaky areas as separate fumigated volumes can be beneficial in

247 preventing excessive fumigant loss.

248 In this particular study the observed HLTs correlated well with the outside wind

249 speeds regardless of whether or not the stairwell doors were closed. The even gas

250 distributions observed with MB and SF fumigations showed that these two fumigants 
251 have similar gas distribution characteristics. In structures where commodities are

252 present distribution of MB and SF gases could be different due to different rates of

253 sorption by the commodities. However, this effect was nonexistent because the mill was

254 free of any stored commodity.

255 The hourly-average outside wind speeds during the fumigations were

256 superimposed on the corresponding concentration plots in Figure 4. While wind speeds

257 varied mostly within a range of 0 to $5 \mathrm{~m} / \mathrm{s}$, the rapid hour-by-hour wind fluctuations were

258 not reflected in the gas concentration curves. Except for the third MB fumigation, HLTs

259 for each fumigation shown in Figure 4 were calculated by dividing the gas concentration

260 curves over time into sections in which wind speeds were either above or below $5 \mathrm{~m} / \mathrm{s}$.

261 During the third MB fumigation at $8 \mathrm{~h}$ the gas concentration curves indicated a sudden

262 drop (Figure 4E), and thus the concentration curves after this time were divided

263 separately. For each divided section, the five concentration curves were first averaged

264 and Equation 2 was fitted to the average concentration over time data. The exposure

265 periods immediately after fumigant releases when concentration differences were

266 greater than $5 \mathrm{~g} / \mathrm{m}^{3}$ were excluded from the HLT calculations. The average estimated

267 HLTs (and SE), average wind speeds, average absolute inside-outside temperature

268 differences, and corresponding elapsed exposure periods are summarized in Table 4.

269 The HLTs for the MB and SF fumigations were in range of 3.61 to $28.64 \mathrm{~h}$ and 9.97 to

$27031.65 \mathrm{~h}$, respectively. Williams et al. (2000) suggested HLTs above $24 \mathrm{~h}$ as desirable

271 and any values below $10 \mathrm{~h}$ as undesirable for structural fumigations. They reported

272 HLTs of 8 to $15 \mathrm{~h}$ to be common in food-processing facilities subjected to fumigation.

273 The range of HLTs observed reflects variation among structures in gas tightness 
274 despite effective sealing, since all of the building gaps cannot be accurately identified or

275 sealed. Based on the pressurization test, the Hal Ross flour mill had nearly identical

276 sealing quality based on visual inspection, but the differences in HLTs were observed

277 across the six fumigations. Of all the weather variables observed, only wind speeds

278 predominantly affected HLTs, and HLTs were inversely related to wind speeds (Figure

$2795 A)$.

280 Except for the last two HLTs of the third MB fumigation, when the average wind

281 speeds were not greater than $5 \mathrm{~m} / \mathrm{s}$, the HLTs were longer than $10 \mathrm{~h}$, regardless of the

282 type of fumigant used. The last two HLTs of the third MB fumigation were 3.61 and 9.71

$283 \mathrm{~h}$ while the corresponding average wind speeds were less than $5 \mathrm{~m} / \mathrm{s}$. These two

284 unexpectedly short HLTs were observed after the sudden drop in the fumigant

285 concentration during the third MB fumigation probably due to some seal damage which

286 we could not firmly identify. From Equations 3 and 4, if the stack effect was neglected, it

287 can be seen that:

288

$H L T=\frac{x_{1}}{U}$

289 where, $x_{1}$ is a constant. Discarding the last two short HLTs of the third MB fumigation, 290 fitting Equation 5 to the data in Figure $5 \mathrm{~A}$ resulted in the mean $\pm \mathrm{SE}$ (no. observations =

291 8) $x_{1}$ value of $68.52 \pm 2.85$ and a $r^{2}$ value of 0.922 . Similarly, combining Equations 3 and 2924 with the wind effect neglected yields Equation 6:

293

$$
H L T=\frac{x_{2}}{\sqrt{\Delta T}}
$$

294 where $x_{2}$ is a constant. However, such correlation in Equation 6 could not be

295 established as indicated by the scattered data points of the HLTs plotted against the 296 square roots of the average absolute inside-outside temperature differences in Figure 
297 5B. This was likely attributed to the strong wind effect overshadowing the buoyancy 298 force. Chayaprasert and Maier (2010) found that as the wind speed doubled the HLT

299 decreased by half (Equation 5). Cryer (2008) neglected stack effect in his simulated

300 fumigations and the results indicated that the HLTs for MB and SF were

301 interchangeable. This finding was corroborated by a similar simulation study by

302 Chayaprasert et al. (2009) in which both the wind and stack effects were included in the

303 simulations. The high $r^{2}$ value of the curve fitting result (Equation 5) in the present study

304 indicated a strong correlation between the HLTs and wind speeds rather than the type

305 of fumigant used. In addition, when wind is the dominant force of gas leakage, HLT

306 were inversely proportional to the prevailing wind speed. These empirical findings

307 provide a quantitative basis to support the fact that HLTs are influenced by

308 environmental conditions, which should be taken into consideration during structural 309 fumigations.

310 4. Conclusions

311 This study provided a quantitative side-by-side comparison between MB and SF

312 fumigations in the same flour mill. The pressurization test showed that sealing

313 effectiveness can be quantitatively determined ahead of a fumigation to quantify gas

314 tightness of a structure. The concentrations of both fumigants varied within a range of 2

315 to $7 \mathrm{~g} / \mathrm{m}^{3}$, which implied similar gas distributions with the mill. The observed HLTs

316 decreased with increasing wind speeds regardless of the type of fumigant used. Our

317 results suggest that for a given level of gas tightness of a structure, fumigant leakage

318 rate is a function of the driving forces such as wind speeds rather than inherent gas

319 characteristics of MB and SF. 
320 


\section{Acknowledgements}

322 This study was funded by a 2008 grant from USDA-CSREES Methyl Bromide

323 Transitions Program under agreement number 2008-51102-04583. The authors thank

324 The Industrial Fumigant Company, Olathe, KS, USA, and Presto-X, Omaha, NE, USA, 325 for providing fumigation services. The cooperation of Dow AgroSciences, Indianapolis, 326 Indiana, USA, and Chemtura, West Lafayette, Indiana, USA, is also acknowledged. We 327 thank Sam Hanni, Sara Savoldelli, Lakshmikantha Channaiah, Johnselvakumar

328 Lawrence, Moses Khamis, Monika Brijwani, Xue Meng, James Weaver, Roshan Chetry, 329 Adrian Martinez-Kawas, Carlos Campabadal, and Anne Rigdon for help in monitoring 330 gas concentrations during the six fumigations. This paper is contribution number 12$331 \quad 325-\mathrm{J}$ of the Kansas State University Agricultural Experiment Station. 
334 Annis, P.C., 1999. The relative effects of concentration, time, temperature and other 335 factors in fumigant treatments. In: Zuxun, J., Quan, L., Yongsheng, L., Xianchang,

336 T., Lianghua, G. (Eds), Proceedings of the Seventh International Working

337 Conference on Stored Product Protection, 14-19 October 1998, Beijing, China,

338 Sichuan Publishing House of Science and Technology, Chengdu, China, pp. 331 339337.

340 ASHRAE, 2001. ASHRAE Handbook - Fundamentals. American Society of Heating, 341 Refrigerating and Air-Conditioning Engineers Inc., Atlanta, GA.

342 Banks, H.J., Annis, P.C., 1984. The importance of processes of natural ventilation to 343 fumigation and controlled atmosphere storage. In: Ripp, B.E., Banks, H.J., Bond, 344 E.J., Calverley, D.J., Jay, E.G., Navarro, S. (Eds), Controlled Atmosphere and $345 \quad$ Fumigation in Grain Storages: Proceedings of an International Symposium "Practical 346 Aspects of Controlled Atmosphere and Fumigation in Grain Storages", 11-22 April 347 1983, Perth, Australia, Elsevier, Amsterdam, Netherlands, pp. 299-323.

348 Banks, H.J., Longstaff, R.A., Raupach, M.R., Finnigan, J.J., 1983. Wind-induced 349 pressure distribution on a large grain storage shed: Prediction of wind-driven 350 ventilation rates. Journal of Stored Products Research 19, 181-188.

351 Bell, C.H., Savvidou, N., Wontner-Smith, T.J., 1999. The toxicity of sulfuryl fluoride 352 (Vikane ${ }^{\circledR}$ ) to eggs of insect pests of flour mills. In: Zuxun, J., Quan, L., Yongsheng, 353 L., Xianchang, T., Lianghua, G. (Eds), Proceedings of the Seventh International 354 Working Conference on Stored Product Protection, 14-19 October 1998, Beijing, 
355 China, Sichuan Publishing House of Science and Technology, Chengdu, China, pp. $356 \quad 345-350$.

357 Bell, C.H., Savvidou, N., Wontner-Smith, T.J., Cardwell, S.K., Bodle, C., 2004.

358 Development of sulfuryl fluoride as a fumigant for the milling industry. HGCA Project 359 Report No. 333. London, UK: Home-Grown Cereals Authority.

360 Campbell, J.F., Arbogast, R.T., 2004. Stored-product insects in a flour mill: Population 361 dynamics and response to fumigation treatments. Entomologia Experimentalis et $362 \quad$ Applicata 112, 217-225.

363 Chayaprasert, W., 2007. Development of CFD models and an automatic monitoring and 364 decision support system for precision structural fumigation. Ph.D. Thesis. West

365 Lafayette, IN: Purdue University, Department of Agricultural and Biological $366 \quad$ Engineering.

367 Chayaprasert, W., Maier, D.E., 2010. Evaluating the effects of sealing quality on gas $368 \quad$ leakage rates during structural fumigation by pressurization testing and 369 Computational Fluid Dynamics simulations.pdf. Transactions of the ASABE 53, 853$370 \quad 861$.

371 Chayaprasert, W., Maier, D.E., Ileleji, K.E., Murthy, J.Y., 2008. Development and 372 validation of Computational Fluid Dynamics models for precision structural 373 fumigation. Journal of Stored Products Research 44, 11-20.

374 Chayaprasert, W., Maier, D.E., Ileleji, K.E., Murthy, J.Y., 2009. Effects of weather 375 conditions on sulfuryl fluoride and methyl bromide leakage during structural 376 fumigation in a flour mill. Journal of Stored Products Research 45, 1-9. 
377 Cryer, S.A., 2008. Predicted gas loss of sulfuryl fluoride and methyl bromide during 378 structural fumigation. Journal of Stored Products Research 44, 1-10.

379 Draper, N., Smith, H., 1981. Applied regression analysis, $2^{\text {nd }}$ Ed. John Wiley and Sons, $380 \quad$ New York.

381 Drinkall, M.J., Pye, C.D., Bell, C.H., Braithwaite, M., Clack, S.R., Ive, J., Kershaw, S., 382 2004. The practical use of the fumigant sulfuryl fluoride to replace methyl bromide in 383 UK flour mills. In: Cauvain, S.P., Salmon, S.S., Young, L.S. (Eds), Proceedings of 384 the Twelfth International ICC Cereal and Bread Congress, 23-26 May 2004, 385 Harrogate, UK, Woodhead Publishing, Cambridge, UK, pp. 245-249.

386 Drinkall, M.J., Zaffagnini, V., Süss, L., Locatelli, D.P., 2003. Efficacy of sulfuryl fluoride 387 on stored-product insects in a semolina mill trial in Italy. In: Credland, P.F., Armitage, 388 D.M., Bell, C.H., Cogan, P.M., Highley, E. (Eds), Proceedings of the Eighth 389 International Working Conference on Stored Product Protection, 22-26 July 2002, $390 \quad$ York, UK, CAB International, Wallingford, UK, pp. 884-887.

391 Gandy, D.G., Chanter, D.O., 1976. Some effects of time, temperature of treatment and 392 fumigant concentration on the fungicidal properties of methyl bromide. Annals of $393 \quad$ Applied Biology 82, 279-290.

394 Kenaga, E.E., 1961. Time, temperature and dosage relationships of several insecticidal 395 fumigants. Journal of Economic Entomology 54, 537-542.

396 Reichmuth, C., Rassmann, W., Binker, G., Fröba, G., Drinkall, M.J., 2003. Disinfestation 397 of rust-red flour beetle (Tribolium castaneum), saw-toothed grain beetle 398 (Oryzaephilus surinamensis), yellow meal worm (Tenebrio molitor), Mediterranean 399 flour moth and Indian meal moth (Plodia interpunctella) with sulfuryl fluoride in flour 
400 mills. In: Credland, P.F., Armitage, D.M., Bell, C.H., Cogan, P.M., Highley, E. (Eds),

401 Proceedings of the Eighth International Working Conference on Stored Product

402 Protection, 22-26 July 2002, York, UK, CAB International, Wallingford, UK, pp. 736-

$403 \quad 738$.

404 Small, G.J., 2007. A comparison between the impact of sulfuryl fluoride and methyl

405 bromide fumigations on stored-product insect populations in UK flour mills. Journal

406 of Stored Products Research 43, 410-416.

407 Taylor, R.W.D., 1994. Methyl bromide - Is there any future for this noteworthy fumigant?

408 Journal of Stored Products Research 30, 253-260.

409 U.S.-EPA, 2010. Critical Use Exemption Information. Available at:

410 http://www.epa.gov/ozone/mbr/cueinfo.html. Accessed 17 August 2010.

411 Williams, R.E., Prabhakaran, S., Schneider, B.M., 2000. Monitoring for precision

412 fumigant application in food-processing plants. In, 2000 Annual International

413 Research Conference on Methyl Bromide Alternatives and Emissions Reductions, 6-

4149 November 2000, Orlando, FL.

415 


\section{Figure Captions}

417 Figure 1. Hal Ross flour mill and a generic mill floor plan. Note that only one gas

418 introduction point was selected from one of the two points shown in the figure. Only the 419 southwest and northeast gas monitoring locations are represented in the figure out of 420 the six locations.

421 Figure 2. Results of the building pressurization test for each of the six fumigations.

422 Figure 3. Barometric pressures (A), temperatures (B), and relative humidities (C) 423 recorded by the weather station on the mill roof during each of the six fumigations.

424 Figure 4. Fumigant concentrations over time (solid lines) near the ceiling among all five 425 mill floors and hourly-average outside wind speeds outside the mill (open circles) during 426 the first MB (A) and SF (B), second MB (C) and SF (D), and third MB (E) and SF (F) 427 fumigations.

428 Figure 5. Relationship between HLT values (Table 4) and average wind speeds (A) and 429 HLT values and the square roots of the average absolute inside and outside 430 temperature differences (B). The data points for MB and SF fumigations were plotted as 431 closed circles and closed squares, respectively. The dashed line in A shows Equation 5 432 fitted to the data. Note that the last two HLT values of the third MB fumigation (open 433 circles) were not included in the curve-fitting calculations (see text for details). 
434 Table 1. Quantities of MB and SF fumigants used and gas introduction times.

\begin{tabular}{|c|c|c|c|c|c|c|c|c|c|}
\hline \multirow{2}{*}{ Fumigation } & \multicolumn{2}{|c|}{ Fumigant introduction } & \multirow{2}{*}{$\begin{array}{l}\text { Exposure } \\
\text { period (h) }\end{array}$} & \multicolumn{6}{|c|}{ Introduced amount (kg) on mill floor } \\
\hline & Date & Time & & First & Second & Third & Fourth & Fifth & Total \\
\hline MB1 & 6 May 2009 & $6: 40 \mathrm{pm}$ & 24 & $\begin{array}{c}22.7 \\
+22.7^{a}\end{array}$ & 22.7 & 22.7 & 45.4 & 45.4 & 181.6 \\
\hline SF1 & 27 May 2009 & 6:00 pm & 24.5 & 113.6 & 113.6 & 113.6 & 113.6 & 113.6 & 568.0 \\
\hline MB2 & 11 Aug 2009 & $2: 50 \mathrm{pm}$ & 24 & 22.7 & 22.7 & 22.7 & 45.4 & 45.4 & 158.9 \\
\hline SF2 & 19 Aug 2009 & $2: 45 \mathrm{pm}$ & 24 & 113.6 & 56.8 & 113.6 & 113.6 & 113.6 & 511.2 \\
\hline MB3 & 11 May 2010 & 5:00 pm & 24.3 & $\begin{array}{l}+22.7^{b} \\
+18.1^{c}\end{array}$ & 22.7 & 22.7 & 45.4 & 45.4 & 199.6 \\
\hline SF3 & 25 May 2010 & $5: 10 \mathrm{pm}$ & 25 & 113.6 & 113.6 & 113.6 & $\begin{array}{r}113.6 \\
+28.3^{d}\end{array}$ & $\begin{array}{c}113.6 \\
+28.3^{d}\end{array}$ & 623.7 \\
\hline
\end{tabular}

435 aTop-up (additional gas) release at 9:50 am on 7 May 2009.

$436{ }^{\text {b}}$ Top-up release at 8:15 am on 12 May 2010.

$437{ }^{\mathrm{C}}$ Top-up release at 9:45 am on 12 May 2010.

$438{ }^{\mathrm{d}}$ Top-up release at 7:50 am on 26 May 2010.

439 
440 Table 2. Coefficients (mean $\pm \mathrm{SE}$ ) from Equation 1 fitted to pressure-airflow rate data.

$\begin{array}{ccccc}\text { Fumigation } & \text { No. observations } & b & n & r^{2} \\ \text { MB1 } & 34 & 0.102 \pm 0.007 & 0.655 \pm 0.017 & 0.982 \\ \text { SF1 } & 38 & 0.112 \pm 0.007 & 0.630 \pm 0.016 & 0.978 \\ \text { MB2 } & 38 & 0.105 \pm 0.004 & 0.639 \pm 0.009 & 0.993 \\ \text { SF2 } & 70 & 0.279 \pm 0.031 & 0.445 \pm 0.027 & 0.819 \\ \text { MB3 } & 72 & 0.105 \pm 0.009 & 0.603 \pm 0.021 & 0.916 \\ \text { SF3 } & 77 & 0.098 \pm 0.002 & 0.634 \pm 0.005 & 0.995\end{array}$

441

442 
Table 3. Mean \pm SE values for temperature and relative humidity observed inside the flour mill during fumigations.

\begin{tabular}{cccccc}
\hline \multirow{2}{*}{ Fumigation } & \multicolumn{5}{c}{ Floor } \\
\cline { 2 - 6 } & First & Second & Third & Fourth & Fifth \\
\hline \multicolumn{5}{c}{ Temperature $\left({ }^{\circ} \mathrm{C}\right)$} \\
\hline MB1 & $21.9 \pm 0.009$ & $22.2 \pm 0.010$ & $22.3 \pm 0.014$ & $23.0 \pm 0.014$ & $23.0 \pm 0.008$ \\
SF1 & $23.3 \pm 0.006$ & $24.4 \pm 0.004$ & $25.2 \pm 0.003$ & $25.7 \pm 0.009$ & $25.6 \pm 0.000$ \\
MB2 & $26.7 \pm 0.013$ & $28.6 \pm 0.011$ & $30.0 \pm 0.010$ & $30.9 \pm 0.010$ & $31.1 \pm 0.005$ \\
SF2 & $27.9 \pm 0.005$ & $29.7 \pm 0.009$ & $31.1 \pm 0.002$ & $31.9 \pm 0.001$ & $31.1 \pm 0.000$ \\
MB3 & $23.6 \pm 0.007$ & $23.8 \pm 0.008$ & $24.4 \pm 0.000$ & $24.7 \pm 0.007$ & $25.4 \pm 0.009$ \\
SF3 & $27.6 \pm 0.009$ & $28.3 \pm 0.010$ & $28.4 \pm 0.015$ & $28.9 \pm 0.014$ & $29.3 \pm 0.009$ \\
\hline & & \multicolumn{5}{c}{ Relative humidity (\%) } \\
MB1 & $46.3 \pm 0.097$ & $45.2 \pm 0.088$ & $44.3 \pm 0.056$ & $42.7 \pm 0.064$ & $40.9 \pm 0.080$ \\
SF1 & $43.2 \pm 0.030$ & $40.1 \pm 0.028$ & $37.6 \pm 0.025$ & $36.7 \pm 0.025$ & $34.8 \pm 0.028$ \\
MB2 & $57.6 \pm 0.049$ & $50.6 \pm 0.043$ & $46.0 \pm 0.031$ & $43.5 \pm 0.029$ & $41.3 \pm 0.018$ \\
SF2 & $54.2 \pm 0.027$ & $46.5 \pm 0.064$ & $43.0 \pm 0.023$ & $41.1 \pm 0.031$ & $41.1 \pm 0.031$ \\
MB3 & $34.7 \pm 0.043$ & $33.4 \pm 0.035$ & $32.1 \pm 0.026$ & $31.1 \pm 0.021$ & $29.2 \pm 0.022$ \\
SF3 & $49.8 \pm 0.122$ & $46.5 \pm 0.047$ & $46.0 \pm 0.036$ & $43.1 \pm 0.037$ & $42.1 \pm 0.066$ \\
\hline
\end{tabular}

444

445 
446 Table 4. Mean and SE estimated half-loss times (HLT) and average wind speeds and corresponding elapsed time periods

447 in which these two values were calculated.

\begin{tabular}{|c|c|c|c|c|c|c|c|}
\hline \multirow{2}{*}{ Fumigation } & \multirow{2}{*}{$\begin{array}{l}\text { Elapsed } \\
\text { exposure } \\
\text { period }(h)\end{array}$} & \multirow{2}{*}{$\begin{array}{c}\text { Absolute } \\
\text { average } \\
\text { temperature } \\
\text { difference }\left({ }^{\circ} \mathrm{C}\right)\end{array}$} & \multirow{2}{*}{$\begin{array}{c}\text { Average } \\
\text { wind speed } \\
(\mathrm{m} / \mathrm{s})\end{array}$} & \multicolumn{4}{|c|}{ HLT (h) } \\
\hline & & & & $\begin{array}{c}\text { No. } \\
\text { observations }\end{array}$ & Mean & SE & $r^{2 a}$ \\
\hline \multirow{2}{*}{ MB1 } & $5-15$ & 5.96 & 2.45 & 28 & 28.76 & 0.001 & 0.962 \\
\hline & $17-24$ & 4.03 & 7.12 & 19 & 9.65 & 0.002 & 0.971 \\
\hline SF1 & $5-24$ & 8.00 & 3.67 & 55 & 19.75 & 0.000 & 0.992 \\
\hline MB2 & $5-24$ & 5.35 & 2.16 & 41 & 28.64 & 0.000 & 0.976 \\
\hline \multirow{2}{*}{ SF2 } & $11-21$ & 12.25 & 3.00 & 24 & 28.29 & 0.000 & 0.986 \\
\hline & $21-24$ & 6.01 & 6.90 & 8 & 9.97 & 0.002 & 0.981 \\
\hline \multirow{3}{*}{ MB3 } & $4-8$ & 10.95 & 5.04 & 9 & 10.80 & 0.003 & 0.917 \\
\hline & $8-15$ & 12.50 & 4.93 & 18 & 3.61 & 0.004 & 0.983 \\
\hline & $20-24$ & 10.67 & 3.11 & 10 & 9.71 & 0.003 & 0.967 \\
\hline SF3 & $13-25$ & 4.36 & 2.10 & 26 & 31.65 & 0.001 & 0.955 \\
\hline
\end{tabular}

448

$449{ }^{a}$ The $r^{2}$ values were based on linear regression of hourly fumigant concentration $(y)$ versus elapsed time $(x)$.

450 In an hour, there were 2 to 3 points of average fumigant concentration data. The curve generated from

451 Equation 2 intercepts $y$-axis at $y=C_{i}$ (i.e., the average concentration at the beginning of each fumigant concentration 
452 curve section). Plotting Equation 2 on a semi-log scale gives a straight line, the slope of which is 453 essentially the HLT.

454

455 
Figure 1

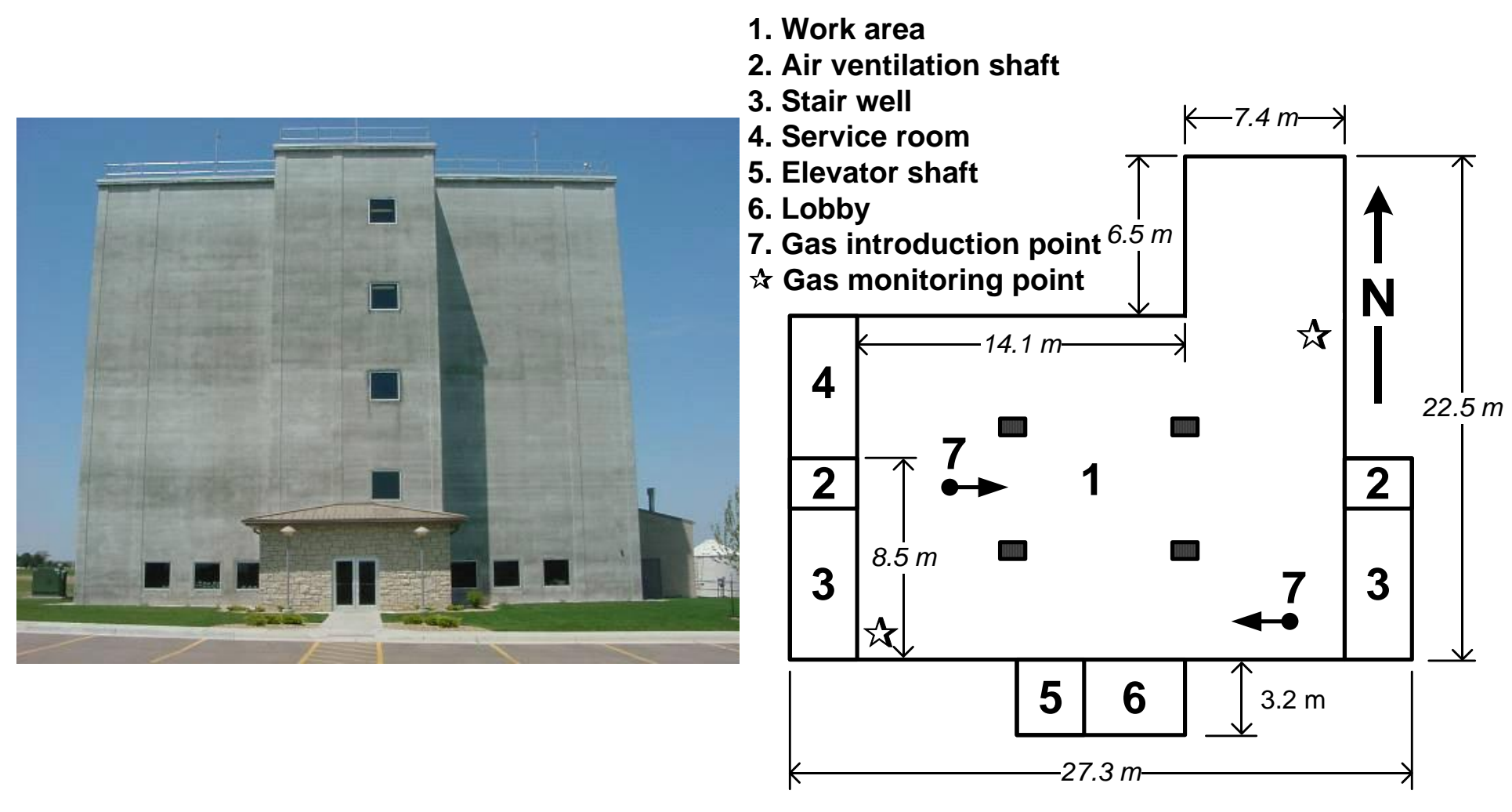

1. Work area

Air ventilation shaft

3. Stair well

4. Service room

5. Elevator shaft

6. Lobby

7. Gas introduction point Gas monitoring point 
Figure 2

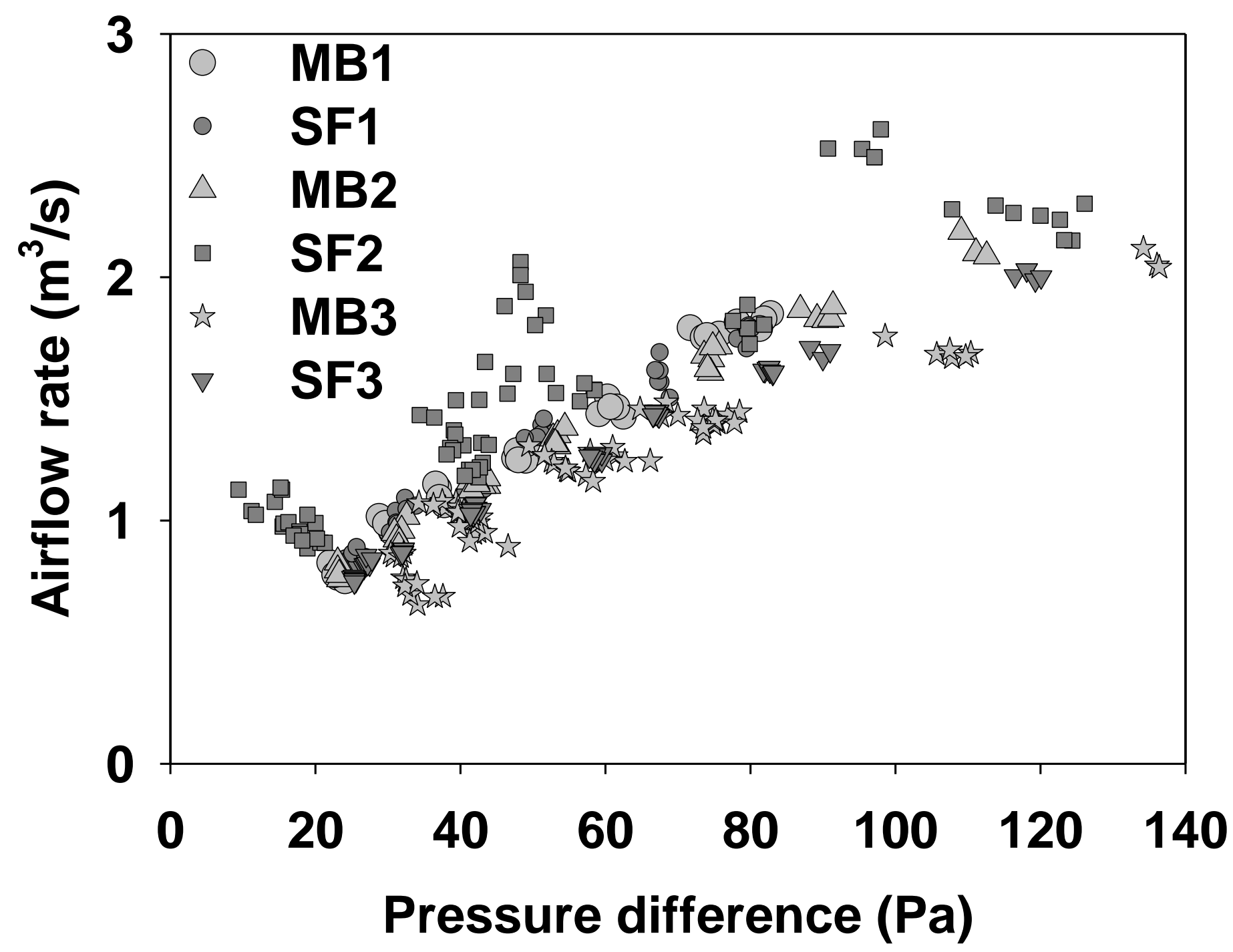


Figure 3
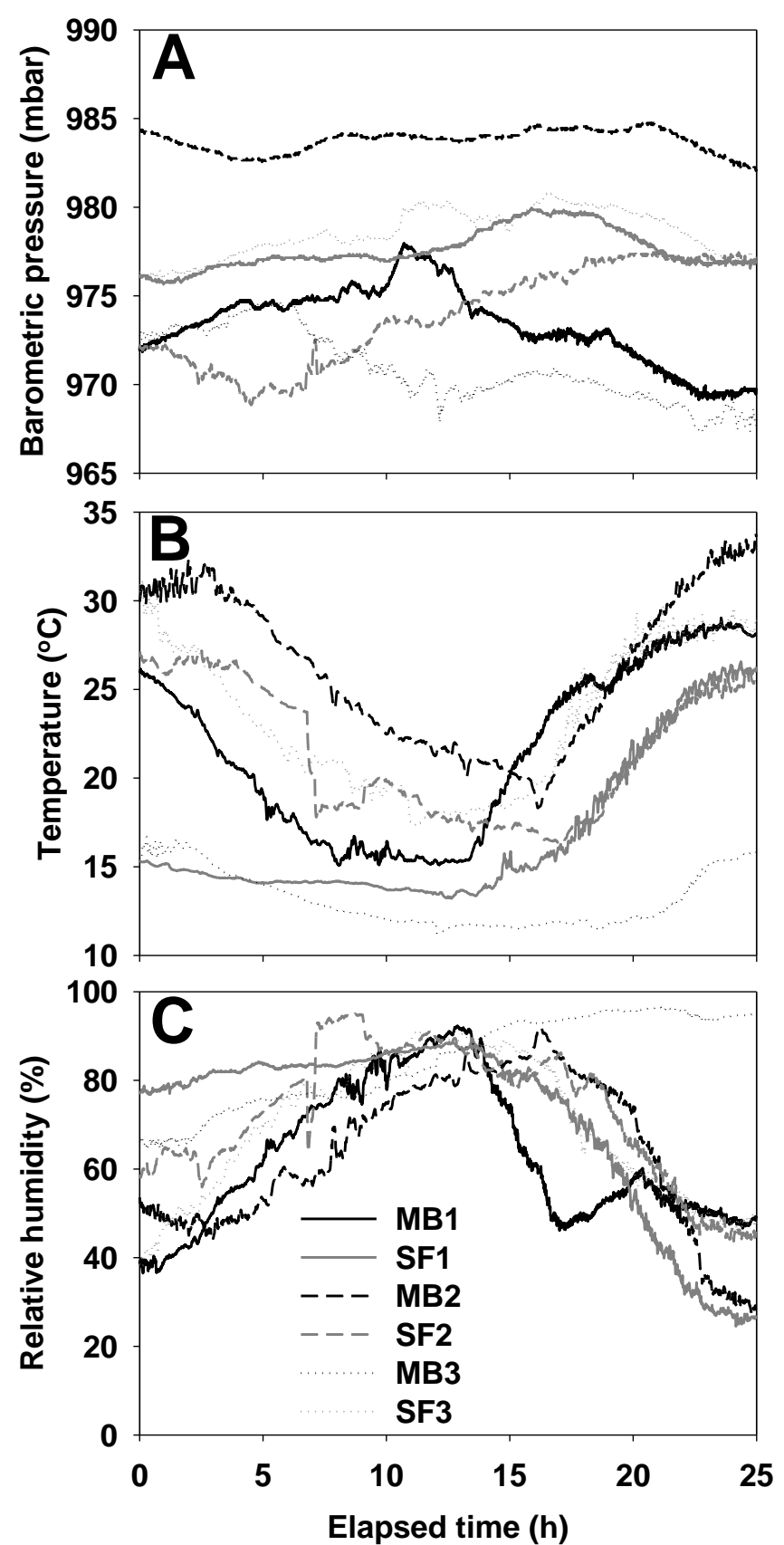
Figure 4
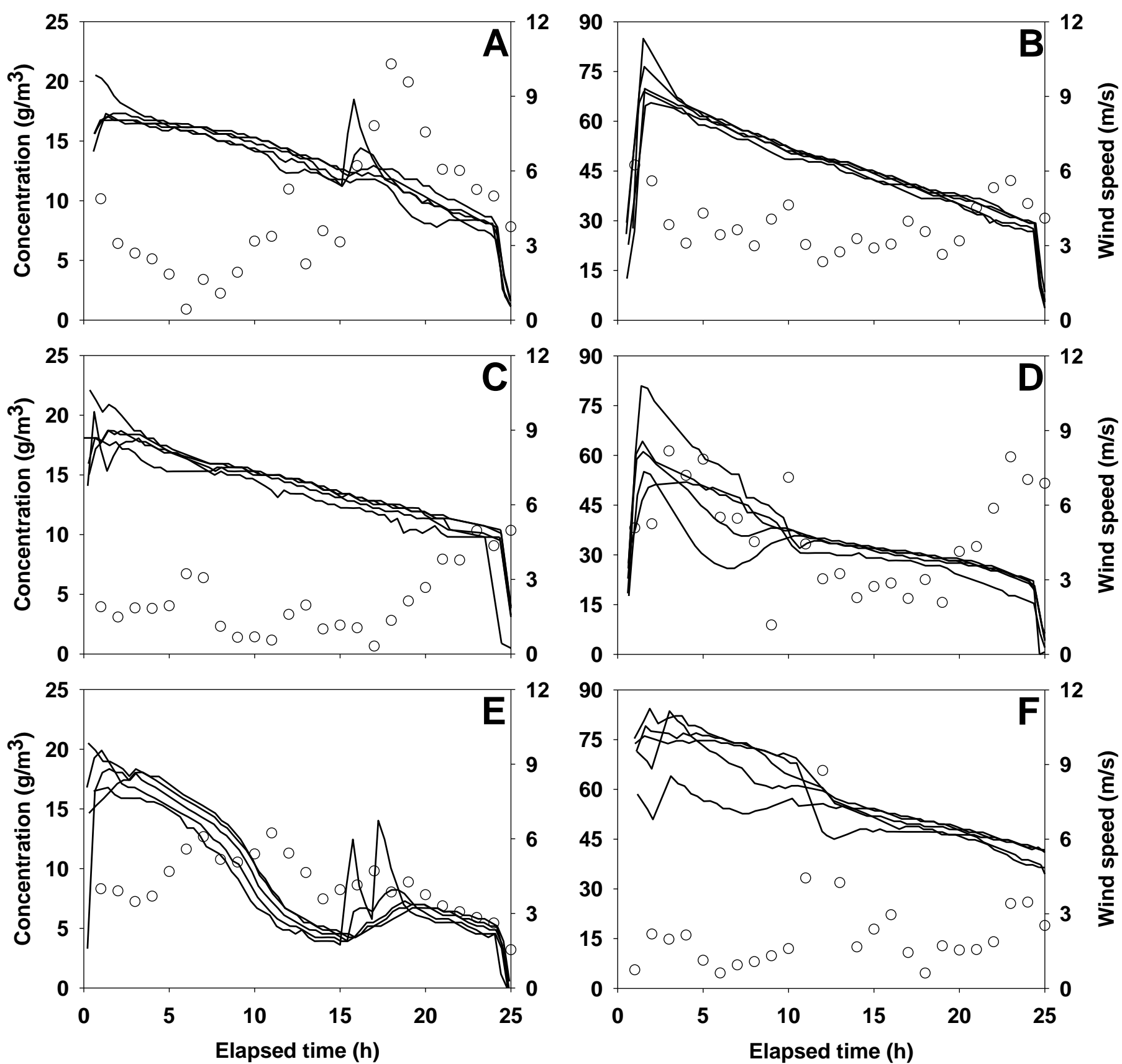
Figure 5
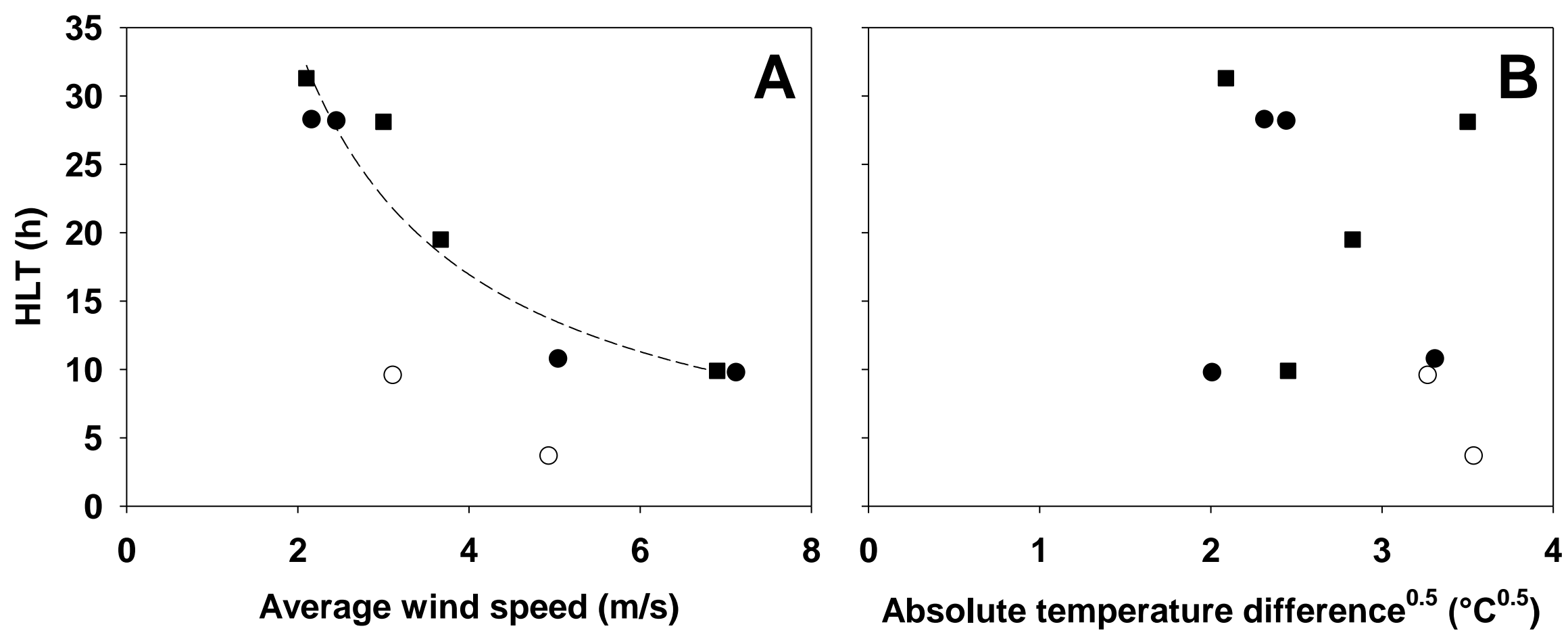